\title{
Environmental exposure of a simulated pond ecosystem to CuO nanoparticle based-wood stain throughout its life cycle
}

\author{
Mélanie Auffan ${ }^{\mathrm{a}, \mathrm{b}, \mathrm{c}^{*}}$, Wei Liu ${ }^{\mathrm{a}, \mathrm{b}}$, Lenka Brousset ${ }^{\mathrm{b}, \mathrm{d}}$, Lorette Scifo ${ }^{\mathrm{a}, \mathrm{b}}$, Anne Pariat $^{\mathrm{a}, \mathrm{b}}$, Marcos Sanles ${ }^{\mathrm{a}}$, \\ Perrine Chaurand ${ }^{\mathrm{a}, \mathrm{b}}$, Bernard Angeletti ${ }^{\mathrm{a}, \mathrm{b}}$, Alain Thiéry ${ }^{\mathrm{b}, \mathrm{d}}$, Armand Masion ${ }^{\mathrm{a}, \mathrm{b}}$, Jérôme Rose ${ }^{\mathrm{a}, \mathrm{b}, \mathrm{c}}$ \\ Indoor aquatic mesocosms were used to assess the behavior of fragmented products of a wood stain containing $\mathrm{CuO}$ \\ nanoparticles in a simulated pond ecosytem for 1 month. Byproducts of degradation containing $\mathrm{Cu}$ are likely to be \\ released during the use and end-of-life of this wood stain. Over two months, a pond ecosystem was mimicked in $60 \mathrm{~L}$ tanks \\ and exposed in environmentally relevant conditions to fragmented products of CuO nanoparticle-based wood stain or \\ pristine $\mathrm{CuO}$ nanoparticles. $\mathrm{Cu}$ (bio)transformation and (bio)distribution within different environmental compartments \\ (e.g. water, sediments, benthic grazers) were carefully analyzed. Because of the presence of the stain matrix, CuO \\ nanoparticles contained in fragmented products were less bio-physical-chemically transformed (dissolution, complexation) \\ with respect to pristine nanoparticles. After 28 days, only $1 \%$ of the $\mathrm{Cu}$ injected following fragmented product exposure \\ remained in the water column $\left(0.08 \mu \mathrm{g} . \mathrm{L}^{-1}\right)$, against $10 \%$ for the pristine CuO nanoparticles $\left(2.67 \mu \mathrm{g} . \mathrm{L}^{-1}\right)$. Among these \\ $\sim 10 \%, \sim 51 \%$ were dissolved $\mathrm{Cu}$ species $\left(1.35 \mu \mathrm{g} \cdot \mathrm{L}^{-1}\right)$. These results are discussed with respect to the ecological \\ compartments in which they accumulated, and to the dose to which aquatic organisms with distinct life traits were \\ exposed.
}

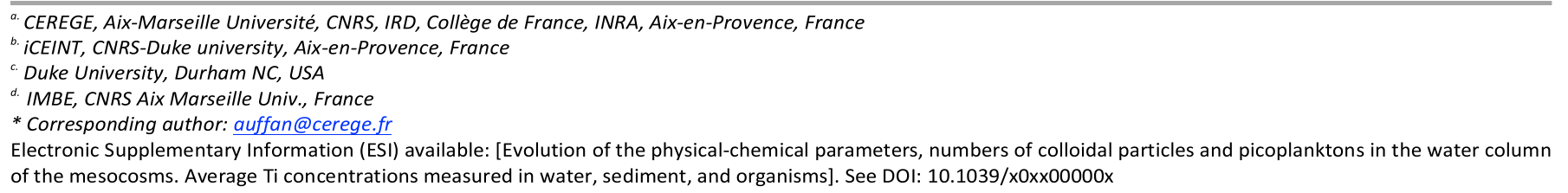

\section{INTRODUCTION}

In a life cycle perspective, research on the release of nanoparticles from nanoproducts is a growing field ${ }^{1}$. Engineered nanoobjects, their aggregates and agglomerates (NOAA) ${ }^{2,3}$ are incorporated in different solid or liquid matrices as in cement ${ }^{4}$, cosmetics ${ }^{5}$, or wood stain ${ }^{6}$ that are used in our everyday lives. These NOAA may be released during the production, the use of the nanoproducts by consumers, but also during their disposal and end-of-life. Gathering information on the release of NOAA at different stages of the value chain is therefore important for defining the hot spots of release and for assessing the human and environmental exposure needed for a realistic risk assessment ${ }^{1}$.

Of the 1814 nanoproducts inventoried in 2015, 31\% used NOAA to confer antimicrobial protection ${ }^{7}$. Among them, antibacterial coatings are of scientific and industrial interests because they are a promising route to potential environmentally friendly applications ${ }^{8}$. They are particularly used in the building industry as indoor and outdoor coatings designed for protection against mold and mildew. Indeed, the use of antibacterial $\mathrm{NOAA}\left(\right.$ e.g. $\mathrm{TiO}_{2}, \mathrm{Ag}, \mathrm{CuO}, \mathrm{CeO}_{2}$ ) decrease the probability of microbial, fungal, and algal growth on the coated surface ${ }^{9,10}$. CuO NOAA are of particular interest because in addition to wood preservation they also provides aesthetic functionality to softwood cladding ${ }^{1}$. Once CuO NOAA-based coatings (e.g. acrylic paint) are applied to the wood, the cupric ions react with carboxylic and phenolic groups from cellulose, hemicellulose and lignin. This leads to the homogenous distribution of the ions in the wood cells, including penetration through cell wall voids ${ }^{11}$ which enhance the bactericidal and antifungal properties. However, at different stages of their value chain all these nano-based coatings are likely to release NOAA ${ }^{6}$ in the environment. In a safe $(r)$ by design perspective, it is worth ensuring about the quantity, the nature, and the speciation of NOAA and their degradation byproducts potentially released during aging, disposal, discharge, etc.

The main goal of this study was to assess in environmentally relevant conditions the behavior and fate of byproducts of degradation containing NOAA likely to be released from CuO NOAA-based acryl paint developed for wood protection. Two main challenges had to be faced: (i) to develop a methodology enabling to speed up the degradation of the paint i.e. to increase the surface area at the paint/water interface while keeping material identical to the one in the real product; (ii) to assess the ecosystem exposure to the paint in environmentally relevant conditions i.e. realistic doses and on the mid-term.

Nowack et al. (2016) developed methods to characterize and quantify NOAA released from composite samples that are exposed to environmental stressors ${ }^{1}$. A quick and reliable approach provided materials in hundreds of gram quantities mimicking actual 
released materials from coatings by producing fragmented products (FP). The elasticity modulus of the matrix was proposed as criterion for FP processing ${ }^{1}$. For matrices with an elasticity modulus in the range of $10^{9} \mathrm{~Pa}$, fragmentation can be performed by cryomilling to simulate the materials' life cycle. However, for viscoelastic matrices, as an acrylic paint $\left(10^{-7} \mathrm{~Pa}\right)$, it needs to be deposit onto a hard substrate before fragmentation. For studies in aqueous media, an alternative was found which consisted in transferring FPs in Milli-Q water just after cryomilling. The fragments suspended in water then avoided merging even at room temperature. This protocol was used to generate FP with larger surface area of the CuO NOAA-based acryl paint used in this study.

Indoor aquatic mesocosms were used to assess the environmental transformation of the latter CuO NOAA-based acryl paint and the ecosystem exposure to the byproducts of transformation. Mesocosms are experimental systems designed to simulate ecosystems ${ }^{12}$ and are an invaluable tool for addressing the complex issue of exposure during nano-ecotoxicological testing. This experimental strategy has already been used to study the behavior or impacts of pristine nanoparticles (i.e. at the first stages of the life cycle) ${ }^{13,14}$ and the release of silver from commercialized nanoproducts ${ }^{15}$. In the current study, indoor aquatic mesocosms $(60 \mathrm{~L})$ were adapted to assess the exposure of ecosystems to the FP of CuO NOAA-based acryl paint (CuO_Acryl_FP) in a fashion that accommodates the control required to elucidate underlying mechanisms at various time and spatial scales ${ }^{16}$. In aquatic ecosystems, CuO_Acryl_FP will be controlled by physical-chemical change (aggregation, sorption of (in)organic substances, redox, etc.) as well as ecological factors (ecological feeding type, trophic transfer potential, etc.). These parameters are most of the time studied separately in the literature. Using indoor aquatic mesocosms, this study will address the (bio)transformation, (bio)distribution and bioavailability of the released materials within different environmental compartments (e.g. water, sediments, biota), and will identify the compartments where concentrations will be the highest ${ }^{16-18}$. Such an approach is undisputable to generate reliable exposure and impact data and for their integration into environmental risk assessment models related to nanotechnologies. In this study, the behavior and fate of CuO_Acryl_FP in a pond ecosystem will be compared to pristine CuO nanoparticles (CUO-NOAA). Because of the presence of paint matrix, we hypothesized that the CuO contained in the FP will be less available to react with their environment (dissolution, complexation) with respect to pristine nanoparticles. Moreover, assuming that the kinetics of bio-physical-chemical transformations of CuO-NOAA and CuO_Acryl_FP would be different, we will assess whether the ecological compartments in which they will accumulate would be impacted.

\section{MATERIAL AND METHODS}

\section{CuO-NOAA and acrylic paint}

Commercial CuO nanopowder (called CUO-NOAA) were provided by PlasmaChem GmbH (Germany). These NOAA were previously characterized by Ortelli et al. (2017). They were spherical with primary average diameter of $12 \pm 8 \mathrm{~nm}$ (TEM size), a specific surface area (BET) of $47 \mathrm{~m}^{2} \cdot \mathrm{g}^{-1}$, an average hydrodynamic diameter in their stock suspension at $140 \pm 5 \mathrm{~nm}$, and an isoelectric point at $\mathrm{pH} 10.3^{11}$. These NOAA were incorporated in acrylic paints serving as reference compounds for wood preservative coating. High-gloss acrylic wood coating containing $43 \%$ white pigment $\mathrm{TiO}_{2}$ (non-nano) passivated with an alumina coating were used ${ }^{19}$. The viscoelasticity of this paint was estimated around $10^{-7} \mathrm{~Pa}$.

\section{Chemical and colloidal stability of CuO-NOAA in batch}

A stock suspension of CuO-NOAA in Volvic ${ }^{\oplus}$ water was prepared at a CuO concentration of 9.9 mg. L $^{-1}$. From this stock, 6 suspensions at $1 \mathrm{mg} \cdot \mathrm{L}^{-1} \mathrm{CuO}$ were prepared in Volvic water with a final volume of $100 \mathrm{~mL}$. Two control beakers with only $100 \mathrm{~mL}$ of pure Volvic ${ }^{\oplus}$ water were also used. Three of them (one control and two CuO-NOAA suspensions at 1 mg. $L^{-1}$ ) were exposed to light using a Philips ${ }^{\oplus} 400 \mathrm{~W}$ Metal halide lamp (UV + visible). The other beakers were covered with aluminum foils and maintained in the dark. After $0,2 \mathrm{~h}, 5 \mathrm{~h}, 1$ day, 2 days, 7 days and 16 days under magnetic stirring, $10 \mathrm{~mL}$ of each suspension were sampled. Ultracentrifugation at $50000 \mathrm{rpm}$ for $1 \mathrm{~h}$ (Ultracentrifuge Beckman Coulter Optima L-100 XP) was used to separate particulate from dissolved $\mathrm{Cu}$. The upper $4 \mathrm{~mL}$ of the supernatant were sampled, acidified $\mathrm{HNO}_{3} 67 \%$, and analyzed by ICP-MS (NexION 300X, Perkin Elmer ) for dissolved Cu. Moreover, the colloidal stability of the CuO-NOAA in Volvic water was evaluated by measuring the size distribution and zeta potential using a Zetasizer NanoZS (Malvern ${ }^{\circledR}$ ).

\section{Fragmentation of the CuO-NOAA-based paint}

The production of fragmented products (FP) of CUO-NOAA treated acrylic paint (called CuO_Acryl_FP) was first optimized to avoid fragment aggregation after milling. Among all the protocols tested, the one leading to the best dispersion in suspension is briefly described herein. Acrylic paint films with $1.5 \%$ (weight) CuO-NOAA were deposited on polyethylene (PE) foils to form solid films after 3 days drying. Before grinding, paint films were removed from the PE foils, cut into ca. $5 \times 5 \mathrm{~mm}$ squares using scissors, placed in a polypropylene disposable vial and stored at -10 - C. $2.5 \mathrm{~g}$ of frozen paint samples were placed into agate mortar for manual grinding. Liquid nitrogen $\left(\mathrm{LN}_{2}\right)$ was immediately added to avoid paint warm-up and manual grinding started simultaneously. Grinding was performed for 2 minutes with regular $\mathrm{LN}_{2}$ addition to compensate for evaporation. Then a sieving at $0.63 \mathrm{~mm}$ was performed in order to eliminate the largest paint FP. After grinding, $\mathrm{LN}_{2}$ was evaporated and $100 \mathrm{~mL}$ of either Volvic ${ }^{\oplus}$ water were used to rinse the tools (pestle and scraper) and collect paint fragments in the mortar. Suspensions of 
CuO_Acrylic_FP in Volvic ${ }^{\oplus}$ water were analyzed by laser granulometry on a MasterSizer 3000 (Malvern ${ }^{\oplus}$ ). Suspensions were mixed vigorously and homogenized before being diluted 50 times to optimize the measurement. Signal average corresponded to 100 measurements with about 1 hour scan for each sample.

\section{Mesocosm set up and dosing}

Mesocosm experiments were implemented using $750 \times 200 \times 600 \mathrm{~mm}$ glass tanks described by ref. ${ }^{16,18}$ (figure 1 ). Briefly each tank is composed by $12 \mathrm{~mm}$-thick monolithic glass panels. Five holes were drilled at mid-height of the tank and were connected to the pump. Mesocosms were designed to simulate pond ecosystems. Therefore, organisms chosen for this study were picoplankton as primary producer (bacteria, algae, protozoa, etc. from natural inoculum) and Great Ramshorm snail (Planorbarius corneus (L., 1758)) as a benthic grazer. The natural inoculum and $P$. corneus were collected in a non-contaminated pond part of the Natura 2000 reserve network (43.3464 N 6.259663 E).
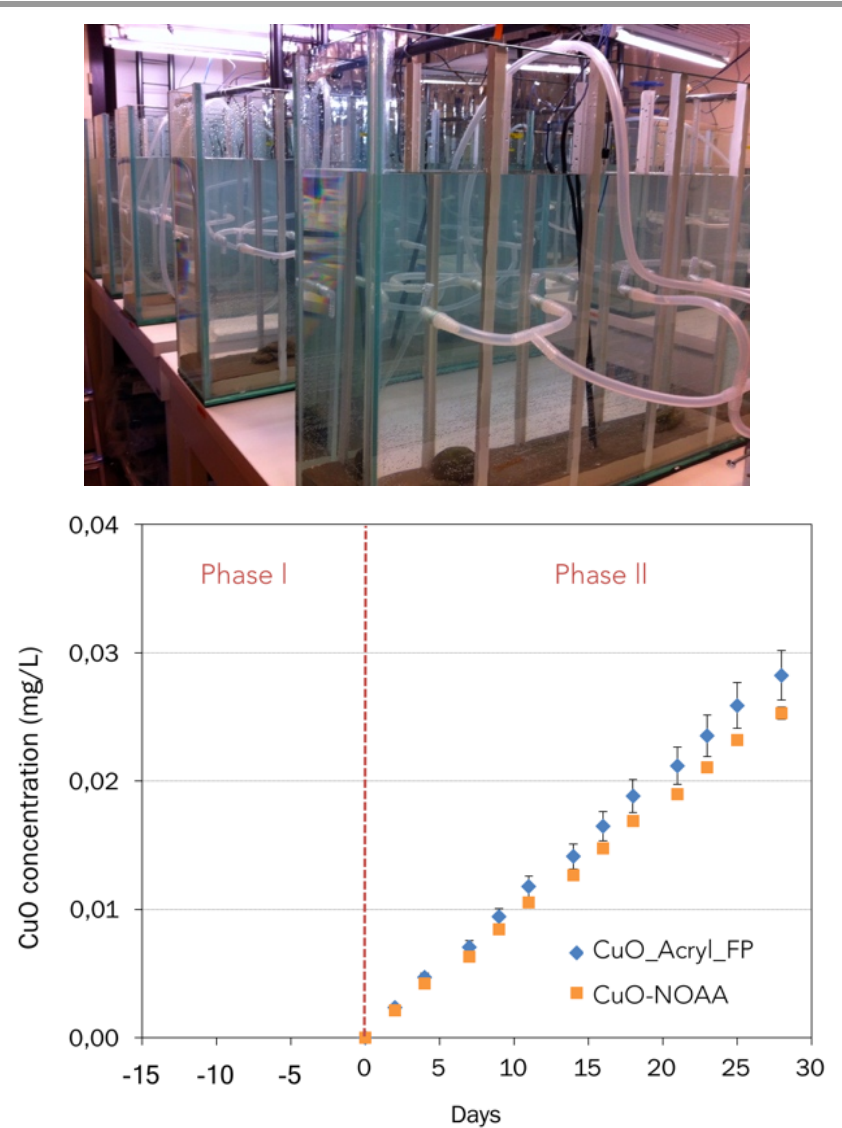

Figure 1. (top) Picture of the indoor aquatic mesocosms. (bottom) Total concentration of CuO injected in the mesocosms following CuO Acryl FP and CuO-NOAA treatment ( 3 times a week for 4 weeks). The concentrations were measured based on the chemical analysis of CuO_Acryl_FP and CuO-NŌAA suspensions used for injections.

Mesocosm experiments required two phases. Phase I launched in October 2015 consisted in the acclimation and equilibration. Tanks were filled with $6-8 \mathrm{~cm}$ artificial sediments containing $89 \% \mathrm{SiO}_{2}, 10 \%$ kaolinite and $1 \%$ of $\mathrm{CaCO}_{3} \mathrm{w} / \mathrm{w}^{16}$. Primary producers were brought by $\sim 300 \mathrm{~g}$ of water-saturated natural sediment (sieved at $200 \mu \mathrm{m}$ ) laid at the surface. The mesocosms were then gently filled with $50 \mathrm{~L}$ of Volvic ${ }^{\odot}$ water with $\mathrm{pH}$ and conductivity close to the natural pond water $\left(\mathrm{pH} 7,11.5 \mathrm{mg} \cdot \mathrm{L}^{-1} \mathrm{Ca}^{2+}, 13.5\right.$ $\left.\mathrm{mg} \cdot \mathrm{L}^{-1} \mathrm{Cl}^{-}, 71 \mathrm{mg} \cdot \mathrm{L}^{-1} \mathrm{HCO}_{3}{ }^{2-}, 8 \mathrm{mg} \cdot \mathrm{L}^{-1} \mathrm{Mg}^{2+}, 6.3 \mathrm{mg} \cdot \mathrm{L}^{-1} \mathrm{NO}_{3}{ }^{-}, 6.2 \mathrm{mg} \cdot \mathrm{L}^{-1} \mathrm{~K}^{+}, 11.6 \mathrm{mg} \cdot \mathrm{L}^{-1} \mathrm{Na}^{+}\right)$. After two days, the physical-chemical parameters were stabilized (turbidity, $\mathrm{pH}$, dissolved $\mathrm{O}_{2}$, redox). Then 19 adult $P$. corneus were added per mesocosm and acclimatized for one week. The organism density and the male/female ratio were selected according to the natural biotope.

Phase II was dedicated to the exposure period to CuO_Acrylic_FP and CuO_NOAA. A multiple dosing scenario was selected on a 4 weeks-period. A total of 12 injections of low and realistic $\mathrm{CuO}$ concentrations were performed as detailed in figure 1 . At the end of the experiment, final concentrations of $28.2 \mu \mathrm{g} . \mathrm{L}^{-1}$ for the CuO_Acryl_FP and $25.3 \mu \mathrm{g} . \mathrm{L}^{-1}$ for the CuO-NOAA were reached (figure 1). In addition, 2 control mesocosms without any dosing in the water column were run. During phase I and II, temperature, $\mathrm{pH}$, conductivity, redox potential, and dissolved $\mathrm{O}_{2}$, were measured every 5 min at mid height of the water column using multi-parameter probes (Odeon ${ }^{\circ}$ Open $\mathrm{X}$ ) and at the water/sediment interface (up to $10 \mathrm{~mm}$ below surficial sediment) and mid height of the sediment using platinum-tipped redox probes. A day/night cycle of $10 \mathrm{~h} / 14 \mathrm{~h}$ was applied using full spectrum 
light (Viva ${ }^{\oplus}$ light T8 tubes $18 \mathrm{~W}$ ), and room temperature was kept constant ${ }^{16}$. A refill with ultrapure water was performed weekly to compensate for evaporation without increasing the conductivity.

\section{Mesocosm sampling and analysis}

Chemical analysis. Due to the high amount of pigmentary $\mathrm{TiO}_{2}$ within $\mathrm{CuO}$ treated paint (43\% of pigmentary $\mathrm{TiO}_{2}$ in mass), we attempted to use titanium as tracer of the paint. Then, the distribution of $\mathrm{Cu}$ and $\mathrm{Ti}$ in the mesocosms was quantified by $\mathrm{Cu}$ and $\mathrm{Ti}$ contents in surficial sediments (depth of sampling estimated about $0.9 \pm 0.4 \mathrm{~cm}$ ) ${ }^{18}$, in the water column (at $\sim 10 \mathrm{~cm}$ from the air-water interface), and in the dissected digestive glands of $P$. corneus using ICP-MS (Nexlon 300X, Perkin Elmer ${ }^{\circ}$ ). Surficial sediments were sampled at three different locations and pooled before drying. All the samples were digested at $180^{\circ} \mathrm{C}$ in an UltraWAVE microwave digestion system. Water samples $\left(2 \mathrm{~mL}\right.$ ) were digested with $1 \mathrm{~mL} \mathrm{HNO} \mathrm{H}_{3} 67 \%$ (Normatom ) and $0.5 \mathrm{~mL} \mathrm{HF}$ 47\%-51\% (PlasmaPure ). For sediment samples $\left(50 \mathrm{mg}\right.$ ), a mixture of 3 acids $\left(1 \mathrm{~mL} \mathrm{HCl} 34 \%\right.$ (Normatom), $2 \mathrm{~mL} \mathrm{HNO} \mathrm{H}_{3} 67 \%, 0.5$ $\mathrm{mL} \mathrm{HF} \mathrm{47 \% -51 \% )} \mathrm{was} \mathrm{used.} \mathrm{Finally,} \mathrm{digestive} \mathrm{glands} \mathrm{of} P$. Corneus were dissolved in $1 \mathrm{~mL} \mathrm{HNO}_{3} 67 \%, 0.5 \mathrm{~mL} \mathrm{H}_{2} \mathrm{O}_{2} 30 \%-32 \%$

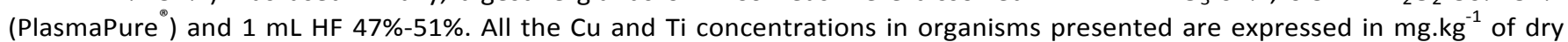
matter. Moreover, the dissolved concentrations of $\mathrm{Cu}$ and $\mathrm{Ti}$ in the water column was assessed using ultrafiltration (Amicon tubes, 3KDa) and filtrate measurements by ICP-MS (Nexlon 300X, Perkin Elmer ${ }^{\circ}$ ). Other elements were also measured in the water column, sediments, and digestive glands (as $\mathrm{Mg}, \mathrm{Zr}, \mathrm{Ni}, \mathrm{Mo}, \mathrm{Sr}$ ), in order to use them as potential internal tracers. Each measurement was performed in triplicate and the measurement quality was controlled using certified reference materials (as mussel tissues CE278k C1 from ERM ${ }^{\circ}$ ).

Particle counting. The number of colloidal particles suspended in mesocosm water columns were monitored at $10 \mathrm{~cm}$ below the water surface using an optical particle counter (Occhio Flowcell FC200S + HR) once a week.

Picoplankton counting. Picoplankton (with cells between 0.2 to $2 \mu \mathrm{m}$ ) concentrations were determined at the surface of the sediment $(0.5 \pm 0.1 \mathrm{~mm}$ depth) and in the water column (10 $\mathrm{cm}$ below the air-water interface) on a weekly basis. Five $\mathrm{mL}$ of water and $15 \mathrm{~mL}$ of sediment were sampled, treated with formaldehyde (3.7\%), and stored at $4^{\circ} \mathrm{C}$ before counting. Before picoplankton counting, $1 \mathrm{~mL}$ of each water column sample was centrifuged $\left(5.9 \times \mathrm{g}\right.$ at $4^{\circ} \mathrm{C}$ for $\left.15 \mathrm{~min}\right)$, and $200 \mu \mathrm{L}$ of each sediment sample was treated with $800 \mu \mathrm{L}$ of $0.1 \mathrm{mM}$ sterile tetrasodium pyrophosphate and vortexed with a steel ball for 30 seconds. For the counting, $10 \mu \mathrm{L}$ of each sample was mixed with $5 \mu \mathrm{L}$ of $3 \mu \mathrm{M}$ SYTO 9 Green Fluorescent Nucleic Acid Stain and dropped on a glass slide. Concentration of picoplankton was the mean \pm standard deviation of five counts.

\section{Statistical analysis}

All the analyses were performed in triplicate and the mean and the standard deviation of the results were presented. The analysis of variance (ANOVA) method was used to test the statistical significance of the results, and a probability values ( $p$ ) less than 0.05 was considered as statistically significant. Statistical significant differences were pointed by asterisk.

\section{RESULTS AND DISCUSSION}

\section{Colloidal and chemical instability of CuO-NOAA in Volvic ${ }^{\circledR}$ water}

To optimize the design of the exposure in indoor aquatic mesocosms (sampling, duration, analysis, etc.), and to better understand the physical-chemical mechanisms of transformation of CUO-NOAA, a preliminary exposure of the CuO-NOAA in abiotic Volvic ${ }^{\circ}$ water was performed. The objectives of this experiment were to determine the colloidal stability of CuO-NOAA and their kinetics of dissolution over time ( $2 \mathrm{~h}, 5 \mathrm{~h}, 1$ day, 2 days, 7 days, 16 days) in conditions close to the water column of mesocosms. This experiment was performed in batch by varying the illumination regimen.

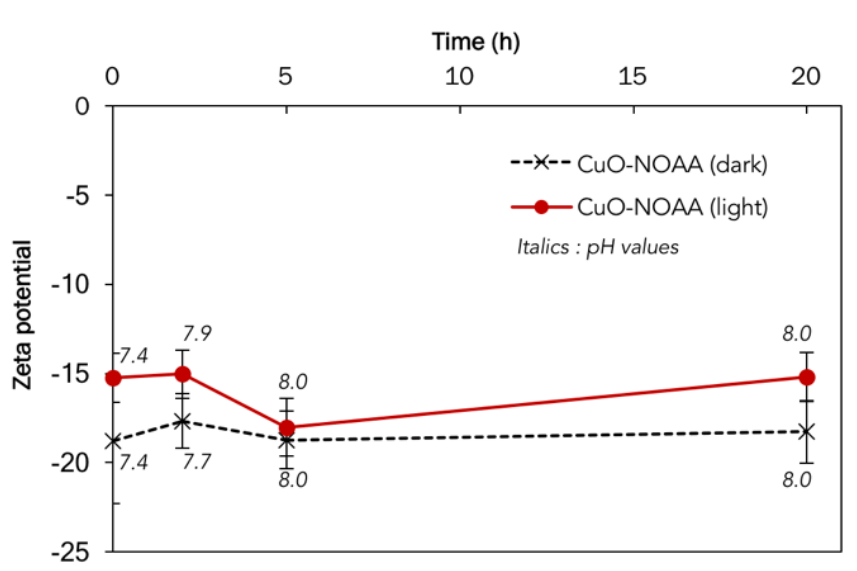


Zeta potential of CuO-NOAA suspension was measured just after the exposure $\left(\mathrm{t}_{0}\right)$ to Volvic ${ }^{\bullet}$ water around $-15 \mathrm{mV}$ and $-20 \mathrm{mV}$ $(\mathrm{pH}$ 7.4). It slightly fluctuated over the first $20 \mathrm{~h}$ of experiment but did not show any significant difference between light and dark conditions (figure 2). The higher zeta potential measured for CuO-NOAA suspensions exposed to UV-visible radiation were not taken as a relevant feature since it was also observed at $t_{0}$ before light could have had any influence. The lack of significant effect of illumination regimen on the stability of the CuO nanoparticles dispersions was also observed by Cheloni et al. (2016) on the short-term $(<24 \mathrm{~h})^{20}$. The zeta potential values obtained in Volvic water highlighted the colloidal instability of the CuO-NOAA as already observed ${ }^{21}$. Misra et al. (2012) have shown that isotopically modified CuO nanoparticles agglomerated and started to sediment in freshwater water within an hour ${ }^{22}$. Due to this instability, no zeta potential measurement could be done for durations longer than 20 hours (figure 2). This aggregation corroborates the lack of accurate size measurements of CuO nanoparticles in aqueous environment in the literature ${ }^{22}$.
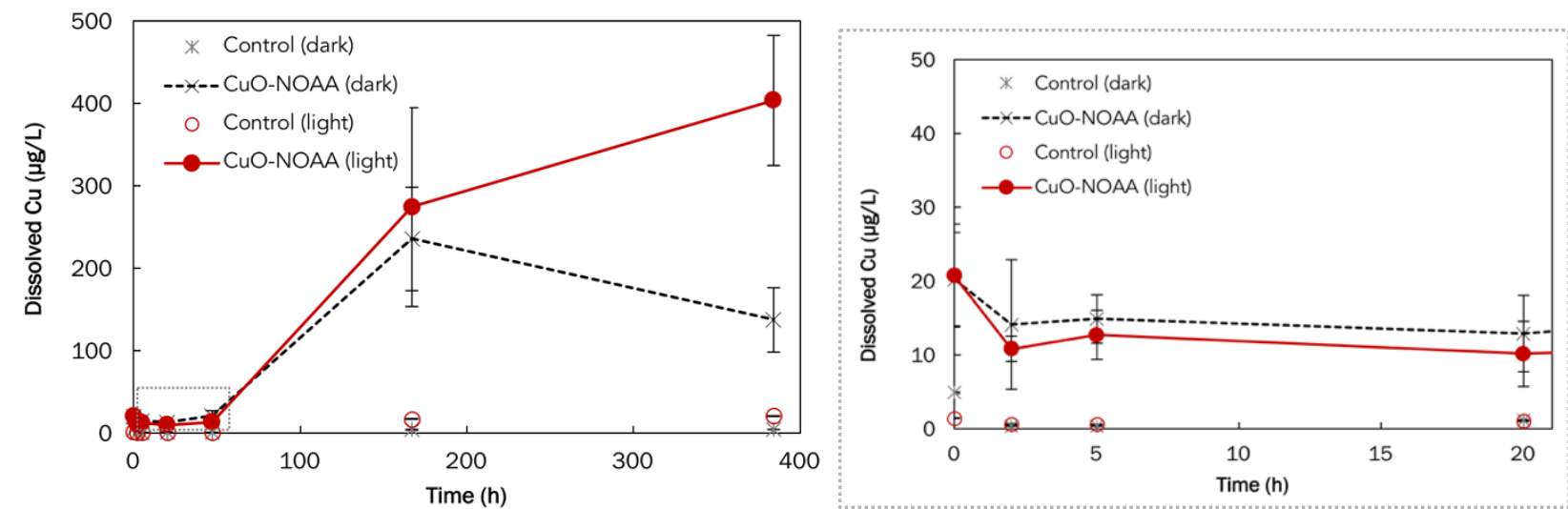

Figure 3. Dissolved Cu vs. time in Volvic water. Each point was an average ( \pm standard deviation) of three replicates for CuO-NOAA suspensions exposed to light or dark conditions and controls. The dotted rectangular corresponds to a zoom in on the first hours of experiment.

CUO-NOAA dissolution was assessed over time and in dark and light conditions. Dissolved Cu concentrations measured in presence of CUO-NOAA suspensions were significantly higher than background concentrations measured in control beakers $(\sim 1$ $\left.\mu \mathrm{g} . \mathrm{L}^{-1}\right) . \mathrm{Cu}(\mathrm{OH})_{2}$ is expected to be the principal cationic hydrolysis product in the Volvic water. Kinetics of $\mathrm{Cu}$ dissolution are given in Figure 3. Cu release remained limited to $1 \%$ to $2.5 \%$ (10 to $20 \mu \mathrm{g} \cdot \mathrm{L}^{-1}$ ) during the first two days of experiment, and increased up to $\sim 30 \%$ after 7 days $\left(\sim 250 \mu \mathrm{g}^{-L^{-1}}\right)$ whatever the illumination regimen was. Cheloni et al. (2016) explored the effect of light with different spectral composition on the chemical stability of CuO nanoparticle and their effects to green alga (Chlamydomonas reinhardtii). Their results showed that simulated natural light and light with enhanced UVB radiation did not affect the dissolution of $\mathrm{CuO}$ nanoparticles ${ }^{20}$ on the short-term $(<24 \mathrm{~h})$. Interestingly, while not illumination regimen-dependent during one week, the dissolution process became light-sensitive after 16 days of aging with $50 \%$ of dissolved Cu under UV-visible light against $\sim 20 \%$ in the dark (figure 3). Such a dissolution of CuO nanoparticles appeared to be the key factor triggering the reactive oxygen species (superoxide anions, hydrogen peroxide) and DNA damage responses in bacteria (Escherichia coli) at low sub-toxic levels $\left(0.1 \mathrm{mg} \mathrm{Cu} . \mathrm{L}^{-1}\right)^{23}$.

Based on these results, a fast aggregation and sedimentation of the CuO-NOAA was expected in the mesocosm water column. Moreover, since in mesocosms CuO-NOAA were exposed to $10 \mathrm{~h} /$ day irradiation during 28 days (less intense irradiation compared to the batch experiment but longer duration), a significant dissolution of CuO-NOAA was also expected in the water column.

\section{Fast aggregation and sedimentation of CuO_Acryl_FP in Volvic ${ }^{\circledR}$ water}

FP were generated following a protocol corresponding to (i) the preparation of CuO NOAA-based acrylic paint film on PE foils, (ii) the mortar grinding of paint film (removed from PE) in liquid nitrogen, and (iii) the transfer of FP to an aqueous phase before complete warm up to room temperature. When the FP were transferred to Volvic ${ }^{\circledR}$ water, size distribution measurements show that the average hydrodynamic diameters of the FP were larger than tens or even hundreds of microns. Freshly prepared suspension of CuO_Acryl_FP exhibited one size mode with $D_{10}=20 \pm 4 \mu \mathrm{m}, D_{50}=73 \pm 29 \mu \mathrm{m}$ and $D_{90}=190 \pm 86 \mu \mathrm{m}$. The diameter $D_{10}$, $D_{50}$, and $D_{90}$ represents the smallest $10 \%, 50 \%$ and $90 \%$ of the particles in volume metrics. With time (two days), the hydrodynamic size distribution shifted to larger sizes with $D_{10}=28 \pm 4 \mu \mathrm{m}, D_{50}=140 \pm 30 \mu \mathrm{m}$ and $D_{90}=434 \pm 117 \mu \mathrm{m}$ (Figure 4). Based on these hydrodynamic diameter values, we expected that the aggregation and settling down of the CuO_Acryl_FP would be fast in the water column of the mesocosms. Such strong colloidal instability was also observed in artificial freshwater using FP of epoxy, polyolefin, polyoxymethylene, and cement containing nanoparticles ${ }^{24}$. 


\section{Favorable bio-physical-chemical conditions in mesocosms}

Contamination (phase II) took place 3 times a week during 28 days. During Phase II, several physical-chemical and microbial parameters were monitored to assess the global response of the mesocosms to the presence of CUO-NOAA and CUO_Acryl_FP. Physical-chemical parameters monitored during the whole experiment were constant during the contamination period: dissolved $\mathrm{O}_{2}\left(11.1 \pm 0.6 \mathrm{mg} \cdot \mathrm{L}^{-1}\right)$, redox potential $(287 \pm 3 \mathrm{mV})$ and $\mathrm{pH}(8.1 \pm 0.1)$ (see SI, Figure S1). ORP probes indicated that the water column was oxidative $(c a+290 \mathrm{mV})$, while reductive conditions prevailed in the sediments $(c a-370 \mathrm{mV})$. Conductivity increased step by step from Day $0\left(245 \pm 1 \mu \mathrm{S} . \mathrm{cm}^{-1}\right)$ to Day $28\left(288 \pm 0.4 \mu \mathrm{S} . \mathrm{cm}^{-1}\right)$. Conductivity drops were recorded during the weekly refills with ultrapure water to compensate the evaporation. On the whole, no significant differences were observed between controls and contaminated mesocosms.

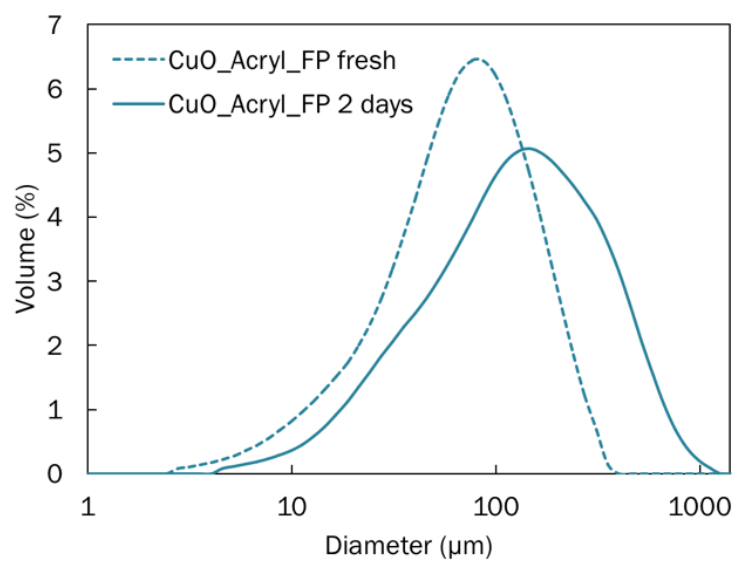

Figure 4. Hydrodynamic diameters measured on the CuO_Acryl_FP freshly prepared suspensions and 2 days-aged suspensions in Volvic ${ }^{\circ}$ water.

Natural suspended particles are also important to monitor since they control the transport of nanoparticles in the environment

${ }^{25}$. At Day $0,40 \%$ of the colloidal particles were in the 0.4 and $0.9 \mu \mathrm{m}$ size fraction whatever the mesocosms were (see $\mathrm{SI}$, Figure S2). Overtime, no statistical difference $(p>0.05)$ was observed between controls and contaminated mesocosms (CuO_NOAA and CUO_Acryl_FP) in term of number of these [0.4 - $0.9 \mu \mathrm{m}]$ colloidal particles. The increase observed at 14 days for the three conditions tested was likely due to the activity of the benthic grazers. Finally, the number of picoplankton (cells between 0.2 and $2 \mu \mathrm{m}$ ) was measured in the water column and surficial sediments (see SI, Figure S2). The total number of cells in surficial sediments remained constant over time and for all conditions tested (ca $10^{7}$ cells. $\mathrm{mL}^{-1}$ ). In the water column, a slight increase was observed from $10^{5}$ cells. $\mathrm{mL}^{-1}$ at Day 0 to $5.10^{5}-10^{6}$ cell. $\mathrm{mL}^{-1}$ at Day 28 . For both the water column and the sediment, no significant differences in the picoplankton number were observed between the controls, contaminated mesocosms (CuO-NOAA and CuO_Acryl_FP). This was already observed with environmentally relevant concentrations of exposure to $\mathrm{CeO}_{2}$ nanoparticles 17,18 . Consequently, during the exposure to FP and NOAA, ecological conditions of the 6 mesocosms remained favorable with oxygenation, $\mathrm{pH}$, temperature, redox potential, suspended material, and number of primary producers in the range of natural conditions.

\section{Material-dependent persistence of $\mathrm{Cu}$ in the water column}

Water and sediment samples were collected at days $0,7,14,21$ and 28. After microwave-assisted digestion of the samples, $\mathrm{Cu}$ and $\mathrm{Ti}$ were quantified by ICP-MS. Indeed, due to the high amount of pigmentary $\mathrm{TiO}_{2}$ within CuO treated paint (43\% of pigmentary $\mathrm{TiO}_{2}$ ), we attempted to use $\mathrm{Ti}$ as tracer of the paint. Figure 5 shows the $\mathrm{Cu}$ concentrations measured in the water column as a function of time. Both $\mathrm{Cu}$ (figure 5) and $\mathrm{Ti}$ (see SI, Figure S3) were detected in the water column of control mesocosms with background concentrations around $1.37 \pm 0.12 \mu \mathrm{g} . \mathrm{L}^{-1}$ for $\mathrm{Cu}$ and $19.2 \pm 17.2 \mu \mathrm{g} . \mathrm{L}^{-1}$ for Ti. The comparison with dissolved concentrations measured after ultrafiltration at $3 \mathrm{kDa}$ revealed that $c a 54 \%$ of the background Cu in controls consisted in ionic species, while ca $98 \%$ of the background $\mathrm{Ti}$ in controls was under particulate form. This was in agreement with the low solubility expected for Ti-based species.

Regarding the mesocosms contaminated with CuO-NOAA, an increase of the total Cu concentration was observed over time (figure 5). After 28 days of experiment, total $\mathrm{Cu}$ concentration rose up to $2.67 \mu \mathrm{g} . \mathrm{L}^{-1}$ in the water column with $1.35 \mu \mathrm{g} . \mathrm{L}^{-}$of dissolved $\mathrm{Cu}$ (ultrafiltration threshold $<3 \mathrm{kDa}$ ). We estimated that $\sim 51 \%$ of the Cu present in the water column and coming from CuO-NOAA was dissolved $(<3 \mathrm{kDa})$. The remaining $\sim 49 \%$ were under particulate form or complexed with organic compound. Indeed, $\mathrm{Cu}(\mathrm{OH})_{2}$ is expected to be the principal cationic hydrolysis product in pure Volvic ${ }^{\oplus}$ water. In this oxidation state $\left(\mathrm{Cu}^{2+}\right)$, copper forms very stable complexes with both organic and inorganic ligands. Such complexation is likely to occur in the water column of the mesocosms.

After removing the background $\mathrm{Cu}$ concentration, we estimated that only $\sim 10 \%$ of the total $\mathrm{Cu}$ injected (in the CuO-NOAA mesocosms) remained in the water column after 28 days. Similar percentage was calculated at 14 days and 21 days. For the 
mesocosms contaminated with CUO_Acryl_FP, no significant increase in $\mathrm{Cu}$ total concentrations nor dissolved concentrations was evidenced in the water column (always below the detection limit of $0.08 \mu \mathrm{g} . \mathrm{L}^{-1}$ ). This result was in agreement with the strong colloidal instability of the CuO_Acryl_FP observed in pure Volvic ${ }^{\circledR}$ water and highlights that the lifetime of the FP in the water column was very short. Using different simulated leaching and UV/rain weathering protocols, Pantano et al. (2018) assess the release of dissolved $\mathrm{Cu}$ from CuO-NOAA-treated wood ${ }^{19}$. The $\mathrm{CuO}$ acrylate barrier applied on the wood appeared to be robust and to release $\mathrm{Cu}$ ions only in low quantities that were easily masked by environmental or technical contaminations ${ }^{19}$. Our results confirm that CuO-NOAA incorporated in the acrylic paint matrix, will lead to negligible release of $\mathrm{Cu}$ ions contrary to pristine CUO-NOAA under environmentally relevant conditions.

\section{Surficial sediments concentrate the pollution}

Figure 6 shows the total $\mathrm{Cu}$ concentrations determined in surficial sediments. As in water samples, $\mathrm{Cu}$ (figure 6) and Ti (see $\mathrm{SI}$, Figure S3) were already present in the uncontaminated sediments of control mesocosms (average of $24.4 \pm 10.5 \mathrm{mg} \mathrm{Cu} . \mathrm{kg}^{-1}$ and

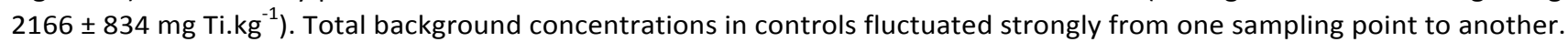

In contaminated mesocosms, no specific trend in $\mathrm{Cu}$ and $\mathrm{Ti}$ total concentrations in surficial sediments were evidenced, with concentrations never significantly different from control mesocosms. However, based on water column concentrations, we estimated that $\sim 90 \%$ of CUO-NOAA and $>99 \%$ of CuO_Acryl_FP injected at Day 28 settled down at the surface of sediments. Assuming that all these $\mathrm{Cu}$ were homogeneously distributed on the sediments, this should have resulted in a maximum increase

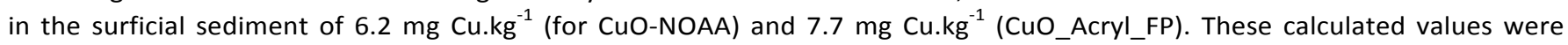
below the standard deviation calculated for the background $\mathrm{Cu}$ and $\mathrm{Ti}$ concentration in sediments of control mesocosms and explained the lack of sensitivity on the ICP-MS measurements in sediments.

Total Cu in water column

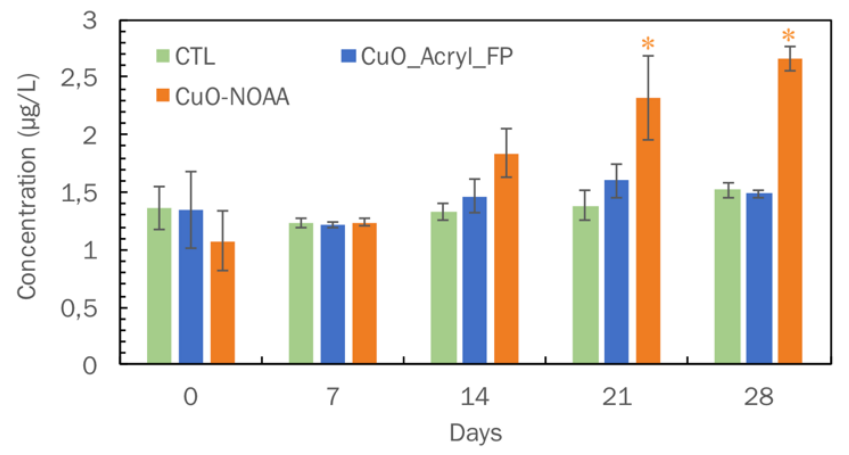

Figure 5. Average total $\mathrm{Cu}$ concentrations measured in the water column at different time points of the experiment for control (CTL) mesocosms and mesocosms contaminated with either CUO_Acryl_FP or CUO-NOAA. Standard deviations observed between replicates were plotted in error bars. ${ }^{*}$ represent data that are significantly different from controls $(p<0.05)$.

To increase the sensitivity of the measurements, the concentrations of $\mathrm{Cu}$ in surficial sediment were expressed as a function of $\mathrm{Ni}$ concentrations that were homogenously distributed in the surficial sediments. The evolution of the $\mathrm{Cu} / \mathrm{Ni}$ ratio over time are presented in figure 7. While no significant increase in the $\mathrm{Cu} / \mathrm{Ni}$ ratio was observed in controls, time-dependent trends were observed for CuO-NOAA and the CuO_Acryl_FP-contaminated mesocosms. After 2 weeks, a significant increase in the Cu/Ni ratio highlight the contribution of $\mathrm{Cu}$ coming from both CuO-NOAA and CuO_Acryl_FP in the surficial sediments. Several mechanisms could explain such an increase of the $\mathrm{Cu}$ concentration in the sediments. This could be related to the complexation of $\mathrm{Cu}$ ions by natural organic matter in the surficial sediments ${ }^{26}$, their adsorption on soil components as clays ${ }^{27}$, or also to the settling down of the CuO-NOAA and the CuO_Acryl_FP.

Based on the strong colloidal instability previously observed, it is likely that the aggregation and settling down mostly governed the increase of the $\mathrm{Cu} / \mathrm{Ni}$ at the surface of the sediment. While homoaggregation of CuO-NOAA is likely to be negligible due to the low particle concentrations expected in freshwaters compared to the concentrations of naturally occurring suspended matter, heteroaggregation attachment is expected to be at the origin of their colloidal instability in freshwater environments. The physical-chemical mechanism of hetero-aggregation of the CuO-NOAA at $\mathrm{pH}=8.1 \pm 0.1$ is related to the electrostatic attraction between the positively charged $\mathrm{CuO}$ and the negatively charged clays (as the lateral charges of kaolinite ${ }^{28}$ ) but also picoplankton (as bacteria, algae) ${ }^{29}$. CuO_Acryl_FP as others breakup/fragmented/released particles of plastics, cement, and paints ${ }^{24,30,31}$ were found very instable as soon as they are put in suspension. Their aggregation in the water column of the mesoscosm was attributed to the large size of the FP $\left(D_{10}=20 \pm 4 \mu \mathrm{m}, D_{50}=73 \pm 29 \mu \mathrm{m}\right.$ and $\left.D_{90}=190 \pm 86 \mu \mathrm{m}\right)$ leading to their fast settling down (Figure 4). 


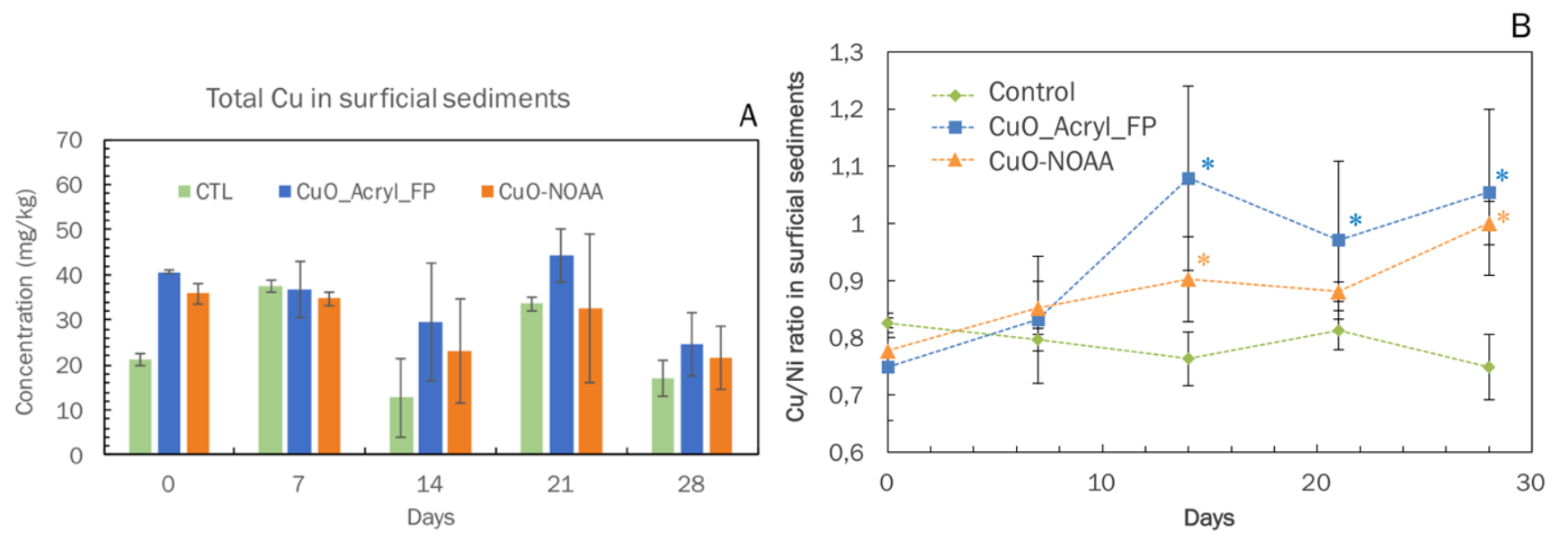

Figure 6. (A) Average Cu concentrations measured in surficial sediments at 0, 7, 14, 21 and 28 days of mesocosms contaminated with CuO Acryl FP or CuO-NOAA and control mesocosms. (B) $\mathrm{Cu} / \mathrm{Ni}$ ratio measured in surficial sediments measured in controls and mesocosms contaminated with CuO Acryl $\overline{\mathrm{FP}}$ or $\mathrm{CuO}-\mathrm{NOAA}$. The standard deviation observed between replicates was plotted in error bars. * represent data that are significantly different from controls $(p<0.05)$.

\section{Interactions with benthic grazers}

$P$. corneus are benthic grazers that eat algae and biofilms at the sediment/water interface. The uptake of Cu from CuO-NOAA and CuO_Acryl_FP by P. corneus was estimated by dissecting, digesting and analyzing the digestive glands of specimens sampled in mesocosms at 7, 14, 21 and 28 days. The concentrations measured for the three different conditions are reported in Figure 7 for $\mathrm{Cu}$, and in Figure S3 in supporting information for Ti. Background $\mathrm{Cu}$ and Ti concentrations were measured in the digestive glands of unexposed organisms around $10.3 \pm 1.5 \mathrm{mg} \mathrm{Cu} . \mathrm{kg}^{-1}$ (dry weight) and around $1.2 \pm 0.4 \mathrm{mg} \mathrm{Ti.kg}{ }^{-1}$ (dry weight). The samples coming from CuO_Acryl_FP and CuO-NOAA mesocosms did not show statistically different concentration with respect to controls. All our attempts to use internal tracers (as $\mathrm{Ni}, \mathrm{Sr}, \mathrm{Zr}, \mathrm{Mo}, \mathrm{Mg}$ ) did not show significant results. As a consequence, the uptake of CuO-NOAA or FP of paint by the organisms was not evidenced, in spite of their strong accumulation at the water/sediment interface. It is noteworthy that the choice of realistically low dosing concentrations for this experiment made the detection of $\mathrm{Cu}$ coming from NOAA or FP in the different compartments extremely difficult and especially in living organisms. Croteau et al. (2014) get around this lack of sensitivity using isotopically modified CuO nanoparticles ( $\left.{ }^{65} \mathrm{Cu}\right)$ to characterize the processes governing $\mathrm{Cu}$ bioaccumulation in a freshwater snail Lymnaea stagnalis. The exposure concentration used in their study was $6.3 \mathrm{mg} \mathrm{Cu} \cdot \mathrm{kg}^{-1}$ of diatoms ${ }^{32}$. In the current study assuming that all the $\mathrm{Cu}$ introduced after 28 days settled down homogeneously at the surface of the sediments, the Cu concentrations coming from the CuO-NOAA and CuO_Acryl_FP would be 6.2 and $7.7 \mathrm{mg} \mathrm{Cu} . \mathrm{kg}^{-1}$ of sediment respectively. Croteau et al. observed that L. stagnalis efficiently accumulated ${ }^{65} \mathrm{Cu}$ after exposure to ${ }^{65} \mathrm{CuO}$ nanoparticles at such a low exposure concentration. They estimated that $80-90 \%$ of the bioaccumulated ${ }^{65} \mathrm{Cu}$ concentration in L. stagnalis originated from the ${ }^{65} \mathrm{CuO}$ nanoparticles, suggesting that dissolution had a negligible influence on $\mathrm{Cu}$ uptake from the nanoparticles under their experimental conditions ${ }^{32}$. The preferential bioaccumulations of dissolved species compared to nanoparticulate forms are known to depend on the lifestyles of the aquatic species (filter feeders versus benthic grazers) ${ }^{17,33}$. Both $L$. stagnalis and $P$. corneus are important grazers in benthic freshwater habitats ${ }^{34}$. They have similar and unspecific ingestion mode through the gastropod radula i.e. their prey selection on the level of individual food items (e.g. algal cells) is not possible ${ }^{35}$. Based on their similar lifestyle compared to $L$. stagnalis, we hypothesized that $P$. corneus would be able to ingest $\mathrm{Cu}$ coming either from settled down CUO-NOAA or CuO_Acryl_FP after exposure in surficial sediments even if nondetected by ICP-MS.

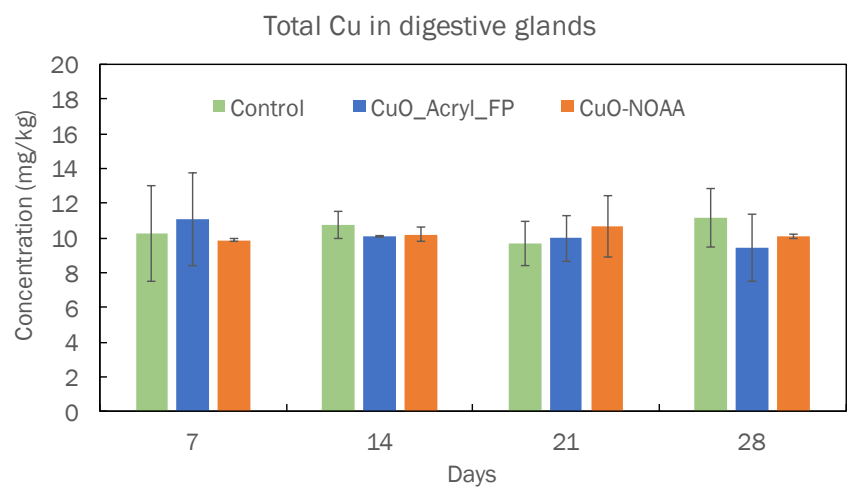

Figure 7. Average Cu concentrations measured in the digestive glands of $P$. corneus sampled at 7, 14, 21 and 28 days in mesocosms contaminated with CuO_Acryl_FP or CuO-NOAA, and control mesocosms. The standard deviation observed between replicates was plotted in error bars. 
We acknowledge that the FP obtained by our approach are not the materials released from paint during their use or disposal, but they represent an interesting approximation and allowed the production of hundred gram quantities of materials for testing in mesocosms. Such an approach allows to compare the behavior and fate in a pond ecosystem of pristine CuO nanoparticles vs. $\mathrm{CuO}$ nanoparticles contained in the FP of an acrylic paint. Because of the paint matrix, we previously hypothesized that (i) the CUO-NOAA would be less available to react with their environment and to be transformed (oxidative dissolution) once incorporated in the acrylic matrix, and (ii) the kinetics of bio-physical-chemical transformations being different between CuONOAA and CuO_Acryl_FP, the ecological compartments in which they will accumulated would differ.

The analysis of the water column and surficial sediments of mesocosms over one month of multiple dosing's of CuO_Acryl_FP and CuO-NOAA confirmed those two hypotheses (Figure 8). Indeed, after 28 days $\sim 10 \%$ of the injected Cu remained in the water column of the CuO-NOAA-contaminated mesocosms (i.e. $2.67 \mu \mathrm{g} . \mathrm{L}^{-1}$ ), while it was below 1\% for CuO_Acryl_FP-contaminated mesocoms. Among these $\sim 10 \%$ of $\mathrm{Cu}$ coming from the CuO-NOAA, $\sim 51 \%$ of the $\mathrm{Cu}$ were dissolved species (i.e. $1.35 \mu \mathrm{g} . \mathrm{L}^{-1}$ ). Bondarenko et al. (2013) reviewed the ecotoxicity of $\mathrm{CuO}$ nanoparticles and $\mathrm{Cu}$ salts toward environmentally relevant aquatic organisms ${ }^{36}$. They calculated median $\mathrm{L}(\mathrm{E}) \mathrm{C}_{50}$ values for dissolved $\mathrm{Cu}$ and nanoparticulate $\mathrm{CuO}$ toward species living in the water column of freshwater ponds. $\mathrm{L}(\mathrm{E}) \mathrm{C}_{50}$ of $\mathrm{Cu}$ salts $\left(\mathrm{CuSO}_{4}, \mathrm{CuCl}_{2}\right)$ were estimated at $0.02 \mathrm{mg} \cdot \mathrm{L}^{-1}$ ( $\mathrm{min}: 0.004 \mathrm{mg} \cdot \mathrm{L}^{-1} ; \mathrm{max}: 0.07 \mathrm{mg} \cdot \mathrm{L}^{-1}$ ) for crustaceans (Daphnia) and at $0.075 \mathrm{mg} \cdot \mathrm{L}^{-1}$ (min: $0.0044 \mathrm{mg} . \mathrm{L}^{-1} ; \mathrm{max}: 13.0 \mathrm{mg} . \mathrm{L}^{-1}$ ) for algae (chlorella sp., Pseudokirchneriella subcapitata, Nitellopsis obtusa). The $\mathrm{L}(\mathrm{E}) \mathrm{C}_{50}$ values of $\mathrm{CuO}$ nanoparticles were measured about $2.1 \mathrm{mg} \cdot \mathrm{L}^{-1}$ (min: $0.08 \mathrm{mg} . \mathrm{L}^{-1}$; max: $12.3 \mathrm{mg} \cdot \mathrm{L}^{-1}$ ) for crustaceans (Daphnia) and at $2.80 \mathrm{mg} \cdot \mathrm{L}^{-1}$ (min: $0.68 \mathrm{mg} \cdot \mathrm{L}^{-1}$; max: $47.0 \mathrm{mg} \cdot \mathrm{L}^{-1}$ ) for algae (Chlorella sp., $P$. subcapitata, N. obtusa) ${ }^{36}$.

The concentration of dissolved Cu released from CuO-NOAA in the water column of the mesocosms after 1 month ( 1.35 $\mu \mathrm{g} . \mathrm{L}^{-1}$ ) was in the lower range of these $L(E) C_{50}$ while particulate $C u\left(\sim 1.32 \mu \mathrm{g} . L^{-1}\right)$ was 60 to 500 times lower than the minimum $L(E) C_{50}$ values. In a lifecycle perspective, these results highlighted that at the early stages (i.e. production and formulation) a specific attention has to be paid to planktonic organisms and filter feeders that could be accidently exposed on the short-term to $\mathrm{Cu}$ ions released from pristine CUO-NOAA. However, during the use and end-of-life stages, the release of Cu from CuO-NOAA incorporated in acrylic paint was very low in the water column and no significant exposure of organisms living and/or feeding in the water column is expected. However, CuO_Acryl_FP (as CuO-NOAA) ended up quickly in surficial sediments (90\% to $99 \%$ of $\mathrm{Cu}$ ) being potentially available for short- and long-term exposure to benthic grazers. In other words, the surficial sediments were found to concentrate the $\mathrm{Cu}$ pollution coming from pristine CuO-NOAA and FP of CuO-based paint in a simulated pond ecosystem at all lifecycle stages i.e. from the production, to the use, and the end-of-life.

During the 28 days of exposure in mesocosms, the survival rates of $P$. corneus $(<2 \%$ of mortality, data not shown) and picoplankton (see SI, Figure S2) was not affected by the presence of CuO-NOAA or CuO_Acryl_FP. No acute toxicity was observed during one month on the two trophic levels i.e. benthic and pelagic picoplankton's and benthic grazers. Nevertheless, a thorough characterization of the biological responses (at the individual, sub-individual, and community level) is still needed to better understand the biological mechanisms of interactions. Indeed, benthic and planktonic microbial communities might be affected by the exposure to nanoparticulate or dissolved $\mathrm{Cu}$ as already observed for bacterial community from soils ${ }^{37}$. Moreover, the exposure of $P$. corneus to $\mathrm{Cu}$ via the surficial sediments might impact the mollusk physiology mainly on the hemolymph regulation; $P$. corneus's hemocyanin being a metalloprotein containing copper atoms reversibly bind to a single oxygen molecule 38

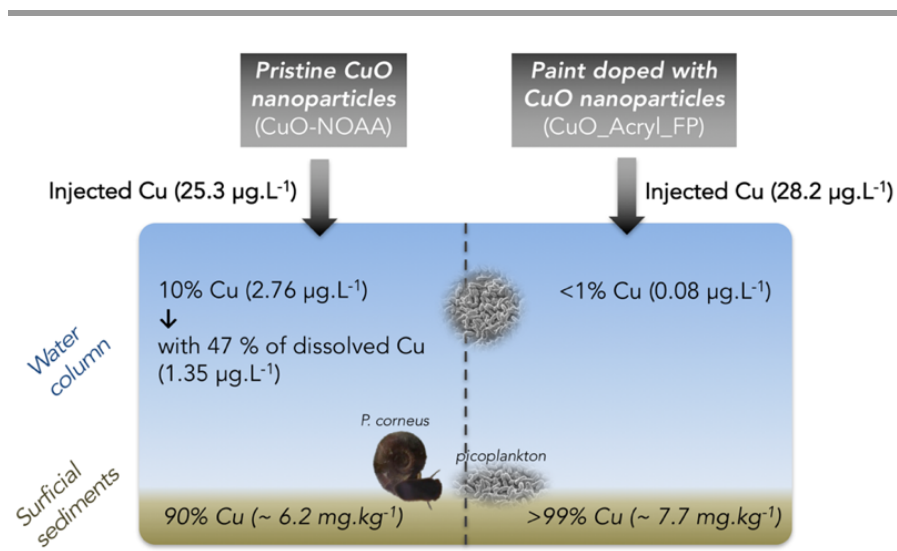

Figure 8. Distribution of the Cu following CuO-NOAA (left) and CuO_Acryl_FP (right) after one month of contamination of freshwater aquatic mesocosm mimicking a pond ecosystem. In italics: calculated values. 


\section{CONFLICTS OF INTEREST}

There are no conflicts of interest to declare.

\section{ACKNOWLEDGEMENTS}

We thank Margareth Swerdloff and Athena Nghiem for their helps during batch experiments. This work was supported by the project on Sustainable Nanotechnologies (SUN) that receives funding from the European Union Seventh Framework Program (FP7) under grant agreement number 604305, and (ii) the French ANR funding for the ANR-3-CESA-0014/NANOSALT program. The project leading to this publication has received funding from Excellence Initiative of Aix-Marseille University - A*MIDEX, a French "Investissements d'Avenir" program, through its associated Labex SERENADE project. This work is also a contribution to the OSU-Institut Pythéas. Finally, the authors acknowledge the CNRS funding for the GDRi iCEINT.

\section{REFERENCES}

1. B. Nowack, A. Boldrin, A. Caballero, S. F. Hansen, F. Gottschalk, L. Heggelund, M. Hennig, A. Mackevica, H. Maes, J. Navratilova, N. Neubauer, R. Peters, J. Rose, A. Schäffer, L. Scifo, S. v. Leeuwen, F. von der Kammer, W. Wohlleben, A. Wyrwoll and D. Hristozov, Meeting the Needs for Released Nanomaterials Required for Further Testing-The SUN Approach, Environmental Science \& Technology, 2016, 50, 2747-2753.

2. I. T. 12901-1, Nanotechnologies - Occupational risk management applied to engineered nanomaterials.Journal, 2012.

3. I. T. 12901-2, Nanotechnologies - Occupational risk management applied to engineered nanomaterials.Journal, 2012.

4. N. Bossa, P. Chaurand, J. Vicente, D. Borschneck, C. Levard, O. Aguerre-Chariol and J. Rose, Micro- and nano-X-ray computedtomography: A step forward in the characterization of the pore network of a leached cement paste, Cement and Concrete Research, 2015, 67, 138-147.

5. C. Botta, J. Labille, M. Auffan, D. Borschneck, H. Miche, M. Cabié, M. A., J. Rose and J.-Y. Bottero, TiO2-based nanoparticles released in water from commercialized sunscreens in a life-cycle perspective : structures and quantities, Environmental Pollution, 2011, 159, 1543-1548.

6. L. Scifo, P. Chaurand, N. Bossa, A. Avelan, M. Auffan, A. Masion, B. Angeletti, I. Kieffer, J. Labille, J.-Y. Bottero and J. Rose, Nonlinear release dynamics for a $\mathrm{CeO} 2$ nanomaterial embedded in a protective wood stain, due to matrix photo-degradation, Environmental Pollution, 2018, in review.

7. M. E. Vance, T. Kuiken, E. P. Vejerano, S. P. McGinnis, M. F. Hochella, Jr., D. Rejeski and M. S. Hull, Nanotechnology in the real world: Redeveloping the nanomaterial consumer products inventory, Beilstein Journal of Nanotechnology, 2015, 6, 1769-1780.

8. A. Kumar, P. K. Vemula, P. M. Ajayan and G. John, Silver-nanoparticle-embedded antimicrobial paints based on vegetable oil, Nature Materials, 2008, 7, 236.

9. S. Meghana, P. Kabra, S. Chakraborty and N. Padmavathy, Understanding the pathway of antibacterial activity of copper oxide nanoparticles, RSC Advances, 2015, 5, 12293-12299.

10. S. Chen, Y. Guo, H. Zhong, S. Chen, J. Li, Z. Ge and J. Tang, Synergistic antibacterial mechanism and coating application of copper/titanium dioxide nanoparticles, Chemical Engineering Journal, 2014, 256, 238-246.

11. S. Ortelli, A. L. Costa, M. Blosi, A. Brunelli, E. Badetti, A. Bonetto, D. Hristozov and A. Marcomini, Colloidal characterization of CuO nanoparticles in biological and environmental media, Environmental Science: Nano, 2017, 4, 1264-1272.

12. FAO, Food and agriculture organization of the united nations.Journal, 2009.

13. J. L. Ferry, P. Craig, C. Hexel, P. Sisco, R. Frey, P. L. Pennington, M. H. Fulton, I. G. Scott, A. W. Decho, S. Kashiwada, C. J. Murphy and T. J. Shaw, Transfer of gold nanoparticles from the water column to the estuarine food web, Nat Nano, 2009, 4, 441-444.

14. G. V. Lowry, B. P. Espinasse, A. R. Badireddy, C. J. Richardson, B. C. Reinsch, L. D. Bryant, A. J. Bone, A. Deonarine, S. Chae, M. Therezien, B. P. Colman, H. Hsu-Kim, E. S. Bernhardt, C. W. Matson and M. R. Wiesner, Long-Term Transformation and Fate of Manufactured Ag Nanoparticles in a Simulated Large Scale Freshwater Emergent Wetland, Environmental Science \& Technology, $2012,46,7027-7036$.

15. D. Cleveland, S. E. Long, P. L. Pennington, E. Cooper, M. H. Fulton, G. I. Scott, T. Brewer, J. Davis, E. J. Petersen and L. Wood, Pilot estuarine mesocosm study on the environmental fate of Silver nanomaterials leached from consumer products, Science of The Total Environment, 2012, 421-422, 267-272.

16. M. Auffan, M. Tella, C. Santaella, L. Brousset, C. Pailles, M. Barakat, B. Espinasse, E. Artells, J. Issartel, A. Masion, J. Rose, M. Wiesner, W. Achouak, A. Thiery and J.-Y. Bottero, An adaptable mesocosm platform for performing integrated assessments of nanomaterial risk in complex environmental systems, Scientific reports, 2014, 4, 5608.

17. M. Tella, M. Auffan, L. Brousset, E. Morel, O. Proux, C. Chaneac, B. Angeletti, C. Pailles, E. Artells, C. Santaella, J. Rose, A. Thiery and J. Y. Bottero, Chronic dosing of a simulated pond ecosystem in indoor aquatic mesocosms: fate and transport of CeO2 nanoparticles, Environmental Science-Nano, 2015, 2, 653-663.

18. M. Tella, M. Auffan, L. Brousset, J. Issartel, I. Kieffer, C. Pailles, E. Morel, C. Santaella, B. Angeletti, E. Artells, J. Rose, A. Thiery and J.-Y. Bottero, Transfer, transformation and impacts of ceria nanomaterials in aquatic mesocosms simulating a pond ecosystem, Environmental Science \& Technology, 2014, 48, 9004-9013.

19. D. Pantano, N. Neubauer, J. Navratilova, L. Scifo, C. Civardi, V. Stone, F. von der Kammer, P. Müller, M. S. Sobrido, B. Angeletti, J. Rose and W. Wohlleben, Transformations of Nanoenabled Copper Formulations Govern Release, Antifungal Effectiveness, and Sustainability throughout the Wood Protection Lifecycle, Environmental Science \& Technology, 2018, 52, 1128-1138. 

reinhardtii, Aquatic Toxicology, 2016, 170, 120-128.

21. N. Odzak, D. Kistler, R. Behra and L. Sigg, Dissolution of metal and metal oxide nanoparticles in aqueous media, Environmental Pollution, 2014, 191, 132-138.

22. S. K. Misra, A. Dybowska, D. Berhanu, M. N. Croteau, S. N. Luoma, A. R. Boccaccini and E. Valsami-Jones, Isotopically Modified Nanoparticles for Enhanced Detection in Bioaccumulation Studies, Environmental Science \& Technology, 2012, 46, $1216-1222$.

23. O. Bondarenko, A. Ivask, A. Käkinen and A. Kahru, Sub-toxic effects of CuO nanoparticles on bacteria: Kinetics, role of $\mathrm{Cu}$ ions and possible mechanisms of action, Environmental Pollution, 2012, 169, 81-89.

24. M. J. B. Amorim, S. Lin, K. Schlich, J. M. Navas, A. Brunelli, N. Neubauer, K. Vilsmeier, A. L. Costa, A. Gondikas, T. Xia, L. Galbis, E. Badetti, A. Marcomini, D. Hristozov, F. v. d. Kammer, K. Hund-Rinke, J. J. Scott-Fordsmand, A. Nel and W. Wohlleben, Environmental Impacts by Fragments Released from Nanoenabled Products: A Multiassay, Multimaterial Exploration by the SUN Approach, Environmental Science \& Technology, 2018, 52, 1514-1524.

25. M. Therezien, A. Thill and M. R. Wiesner, Importance of heterogeneous aggregation for NP fate in natural and engineered systems, Science of The Total Environment, 2014, 485-486, 309-318.

26. Z.-L. Ren, M. Tella, M. N. Bravin, R. N. J. Comans, J. Dai, J.-M. Garnier, Y. Sivry, E. Doelsch, A. Straathof and M. F. Benedetti, Effect of dissolved organic matter composition on metal speciation in soil solutions, Chemical Geology, 2015, 398, 61-69.

27. I. Atanassova, Competitive Effect of Copper, Zinc, Cadmium and Nickel on Ion Adsorption and Desorption by Soil Clays, Water, Air, and Soil Pollution, 1999, 113, 115-125.

28. E. Tombacz and M. Szekeres, Surface charge heterogeneity of kaolinite in aqueous suspension in comparison with montmorillonite, Applied Clay Science, 2006, 34, 105-124.

29. A. Thill, O. Zeyons, O. Spalla, F. Chauvat, J. Rose, M. Auffan and A. M. Flank, Cytotoxicity of CeO2 Nanoparticles for Escherichia coli. Physico-Chemical Insight of the Cytotoxicity Mechanism, Environ. Sci. Technol., 2006, 40, 6151-6156.

30. W. Wohlleben, S. Brill, W. Meier Matthias, M. Mertler, G. Cox, S. Hirth, B. von Vacano, V. Strauss, S. Treumann, K. Wiench, L. MaHock and R. Landsiedel, On the Lifecycle of Nanocomposites: Comparing Released Fragments and their In-Vivo Hazards from Three Release Mechanisms and Four Nanocomposites, Small, 2011, 7, 2384-2395.

31. T. Hüffer, A. Praetorius, S. Wagner, F. von der Kammer and T. Hofmann, Microplastic Exposure Assessment in Aquatic Environments: Learning from Similarities and Differences to Engineered Nanoparticles, Environmental Science \& Technology, 2017, 51, 2499-2507.

32. M.-N. Croteau, S. K. Misra, S. N. Luoma and E. Valsami-Jones, Bioaccumulation and Toxicity of CuO Nanoparticles by a Freshwater Invertebrate after Waterborne and Dietborne Exposures, Environmental Science \& Technology, 2014, 48, 10929-10937.

33. P.-E. Buffet, M. Richard, F. Caupos, A. Vergnoux, H. Perrein-Ettajani, A. Luna-Acosta, F. Akcha, J.-C. Amiard, C. Amiard-Triquet, M. Guibbolini, C. Risso-De Faverney, H. Thomas-Guyon, P. Reip, A. Dybowska, D. Berhanu, E. Valsami-Jones and C. Mouneyrac, A Mesocosm Study of Fate and Effects of CuO Nanoparticles on Endobenthic Species (Scrobicularia plana, Hediste diversicolor), Environmental Science \& Technology, 2012, 47, 1620-1628.

34. J. D. Jones, Aspects of respiration in Planorbis corneus L. and Lymnaea stagnalis L. (gastropoda: pulmonata), Comparative Biochemistry and Physiology, 1961, 4, 1-29.

35. S. Groendahl and P. Fink, High dietary quality of non-toxic cyanobacteria for a benthic grazer and its implications for the control of cyanobacterial biofilms, BMC Ecology, 2017, 17, 20.

36. O. Bondarenko, K. Juganson, A. Ivask, K. Kasemets, M. Mortimer and A. Kahru, Toxicity of Ag, CuO and ZnO nanoparticles to selected environmentally relevant test organisms and mammalian cells in vitro: a critical review, Archives of Toxicology, 2013, 87, $1181-1200$.

37. J. Rousk, K. Ackermann, S. F. Curling and D. L. Jones, Comparative Toxicity of Nanoparticulate CuO and ZnO to Soil Bacterial Communities, PLOS ONE, 2012, 7, e34197.

38. M. Gutternigg, S. Bürgmayr, G. Pöltl, J. Rudolf and E. Staudacher, Neutral N-glycan patterns of the gastropods limax maximus, cepaea hortensis, planorbarius corneus, arianta arbustorum and achatina fulica, Glycoconjugate Journal, 2007, 24, 475-489. 